The Lower Carboniferous Flora of the Tweed Basin. By A. G. Long, Berwickshire High șchool.

Primitive pteridosperm ovules from Berwickshire suggested that the integument evolved by fusion of separate sterile lobes around a megasporangium.

Two species of ovules occurred within cupules also composed of sterile cylindrical processes. Such cupules showed features comparable to angiosperm carpels and suggested that the pteridosperm cupule was the precursor of the angiosperm earpel.

Three Lepidodendron specimens showed the transition anatomy botween stem and root without a stigmaria.

The nearest comparable flora was that of the Saalfeld beds in Central Europe.

The Stowe Radio Telescope. By J. M. Osborne, Westminster School, London.

A brief outline of the Stowe radio telescope was given. The original concept was described and the discussion with slides included the results obtained. Their significance in the field of amateur radio astronomy was mentioned.

The Szilard-Chalmers Reaction in Iodobenzene.

T. A. H. Peacocke, St. John's School, Leatherhead.

The original theory of the Szilard-Chalmers reaction explains the retention of iodine-128 in the parent molecule in terms of the recoil energy of the active atom. The recoil energy is about $200 \mathrm{eV}$ and would result in the production of 5-7 free phenyl radicals. An alternative theory recently emphasized by C. N. Walton ${ }^{1}$ considers the total energy release in terms of the electron excitation produced by the $\gamma$-rays emitted following the absorption of the neutron. This energy is greater than the recoil energy by several orders of magnitude and would produce many more iree radicals than the $\tilde{\partial}-7$ predicted by the original theory.

To test the rival theories iodobenzene has been irradiated with neutrons in the presence of scavenger iodine labelled with iodine-131, using the Lido reactor at the Atomic Energy Research Establishment. The accompanying $\gamma$-flux produces considerable radiolysis. To differentiate this from the effect of slow neutrons, some tubes were surrounded with cadmium. The observed retention of iodine-131 was measured in the absence of cadmium $\left(R_{1}\right)$ and in the presence of cadmium $\left(R_{2}\right)$. At neutron fluxes of the order of $10^{8} \mathrm{n} \mathrm{cm}^{-2} \mathrm{sec}^{-1}, R_{2}$ is less than $R_{1}$; as the flux is increased the differences become smaller and at high neutron fluxes become negative. This could be explained in terms of the increased $\gamma$-flux inside the cadmium box as measured with the ferrous sulphate dosimeter. Approximate calculations indicate that $10^{5}$ atoms of scavenger iodine are captured per Szilard event. This indicates the production of at least this number of free radicals, which would give strong support to the electronic excitation theory. The conclusions so far drawn must be tentative and further work is in progress.

Dr. F. P. Bowden, the chairman of the Committee for Scientific Research in Schools, in his closing remarks, said :

"This is the first occasion in the history of the society that scientific research carried out in schools has been presented in a formal discussion before it, which emphasizes the importance, at this moment of time, of science teaching in schools and it shows clearly the high level of ability with which some of our schools are manned on the scientific side. A wide incresse of such research is without. doubt one of our greatest needs in this country. Only a fow days ago $I$ was discussing with a research director of a major industry the implementation of his company's programme for the next five years. It was a highly imaginative programme and of great interest. Its suc. cessful prosecution, and that of similar companies, is vital to the economy of this country.

"It was clear that the programme could not be fully. implemented because sufficient scientific and technical men were not available to carry out the work. There are many things we must do to cope with this situation and to breed more of them. It is clear that the cradle and source of them all is science in schools, and it is there that we must take urgent and effective action. This is one reason why we are grateful to the masters and the schools: who are taking part in this scheme. There is no better way of showing schoolboys that science is an exciting activity than by doing creative work in it under their noses, and frequently with their participation. This is a fairly new scheme and it has developed quite rapidly-about 100 projects are in progress at the present time-but we would like to see it much more widely extended and we would be glad if you would tell your colleagues in other schook throughout the country about it.

"The other reason for our gratitude is a more usual one. One of the main functions and pleasures of the Royal Society is to hear of new scientific work and discoveries and to discuss them on their own merits. This has been an essential function of this meeting and it is very impressive to see the remarkably high scientific quality of the work which has been put before us. Of course, we have heard only a few papers; but it is typical of much of the work which is being carried out.

"We wish to express our thanks to the contributors and to the speakers for the very interesting aftermoon they have given us, and to the president for presiding and taking part in the meeting. His presence here is a visible sign of the effective action which he, the Council and the officers of the society have taken throughout in supporting our committee and the scheme."

R. H. DYBATI

\title{
HYDROXYCINNAMIC ACIDS AND RELATED COMPOUNDS
}

$\mathrm{T}$ HE Plant Phenolics Group recently changed its name to the Phytochemical Group with the object of broadening the scope of its discussions into the whole field of plant products; but for its first meeting under the new title, held in the Department of Chemistry of the University of Sheffiold during September 21-23, it appropriately returned to the topic of plant phenols and in particular to hydroxycinnamic acids. Investigations of the structure and properties of natural products and in particular plant polyphenols have figured prominently in the researches carried out in Sheffield under a founder member of the group, Prof. R. D. Haworth, and these problems continue to interest his recently appointed successor, Prof. W. D. Ollis.

The meeting opened on September 22 under the chair. manship of Prof. Ollis, who welcomed the group to Sheffield. The first speaker, Dr. J. B. Harborne (John
Innes Institute, Hertford), revealed the general back ground to the meeting in a paper entitled "The Occur" rence, Distribution and Function of Hydroxycinnamic Acids in Plants", in which particular emphasis was laid on the taxonomic interest which these acids and their. combined forms possess. They also play a central part in the biosynthesis of many of the more complex plant phenols, and in this context Dr. Harborne made brief mention of the problem of the complete absence in plant tissues of 3,4,5-trihydroxycinnamic acid suggesting that, for example, it may be replaced by gallic acid.

The four speakers who followed dealt with the problems associated with the determination of the structures of compounds recently discovered and found to contain one or more of the known hydroxycinnamic acids.

Prof. L. Birkofer (University of Cologne) unfolded the. story behind the isolation, characterization and structure 
determination of the acylated anthocyanins, pigments from Petunia, Salvia, Raphanus and Matthiola hybrids.

Dr. L. M. Scarpati (University of Rome) discussed in detail the problem of the isomers of chlorogenic acid, showing the caffeoyl ester group to be located at the 5 position of quinic acid in neochlorogenic acid and at the 4 position in 'band 510'. Isochlorogenic acid, a component of coffee beans and for a long time considered to bo an isomer of chlorogenic acid, was revealed as a mixture of three di-O-caffeoyl quinic acids in which the 3,5 isomer predominates.

Dr. D. G. H. Daniels (Cereals Research Station, St. Albans) and Mr. M. O. Naumann (University of Sheffield) in two short communications announced the isolation and characterization of two new types of hydroxycinnamoyl estors, respectively, esters with a long-chain aliphatic (1) diol found in oats and the 2-O-caffeoyl ester of the phenolic glucoside arbutin found in Vaccinium vitis idaea.

The session concluded under the chairmanship of Prof. J. W. Fairbairn and concerned the metabolism of hydroxycinnamic acids in higher plants. Miss J. J. Corner (Low Temperature Research Station, Cambridge) read a paper in which the distribution and formation of the $O$-glucosides and glucose esters of the hydroxycinnamic acids were critically evaluated. Dr. M. H. Zenk (University of Munich) discussed the experimental evidence underlying the important $\mathrm{C}_{6} \mathrm{C}_{3} \rightarrow \mathrm{C}_{6} \mathrm{C}_{1}$ pathway for the formation of plant phenols and proposed a biochemical mechanism for this reaction.
The metabolism of the hydroxycinnamic acids was again considered in the final session on the morning of September 23 when Prof. R. D. Haworth took the chair. Prof. R. A. Thomson (University of Aberdeen) and Prof. $\mathbf{E}$. E. Conn (University of California) discussed the question of the biosynthesis of coumarin from respectively the chemical and biochemical points of view. The pathway of coumarin metabolism was olegantly traced by Prof. Conn, and Prof. Thomson directed attention from a purely chemical point of view to the important stop of ortho-hydroxylation, indicating the possible ways in which this transformation might be achieved.

Prof. W. D. Ollis (University of sheffield) followed with a review of the biogenetic relationships among $\mathrm{C}_{15}$ compounds dorived from cinnamyl precursors; in particular he detailed the possible ways in which the dalbergiones and 4-arylcoumarins might be formed and propounded a theory of oxidative biogenesis to explain the production of the associated benzophenones.

The final paper in the meeting was read by Dr. $M$. Zucker (Agricultural Experimental Station, Connecticut) and concerned an investigation of the biogenesis of chlorogenic acid showing that this is believed to involve a transformation of phenylalanine $\rightarrow$ cinnamic acid $\rightarrow 3-0$ cinnamoylquinic acid $\rightarrow 3-O$-p-coumaroylquinic acid $\rightarrow$ chlorogenic acid.

The meeting was well attended, and the lively formal and informal discussions which followed many of the lectures indicated the interest in phytochemical problems which it is the Group's policy to discuss.

\section{POP-OUTS ON CONCRETE SURFACES}

$\mathrm{T}$ HE term 'pop-out' is technically applied to a particular type of disruption or disintegration of concrete surfaces, in serious cases only shortly after casting, with rather special significance. The subject has recently been discussed in a paper by G. M. Idorn (Concrete Research Laboratory, Karlstrup, Denmark) entitled "A Concrete Jetty with Frost Damage" (Magazine of Concrete Research, Coment and Concrete Association, 16, No. 47; 1964).

Mr. Idorn finds that pop-outs on concrete surfaces usually result from exposure to freezing and thawing, involving swelling pressure from ice in certain types of coarse aggregate occurring in Danish gravels. "Pure and silicified limestones and opaline and chalcedonic porous chorts in Danish aggregates are liable to give such pop-outs. These rocks account for about 20-40 per cent in ordinary gravel aggregates (considerably less in the sands).... There is always the possibility that a pop-out has developed because of the swelling pressure from alkali-silica gel in a porous rock particle when it contains or consists of opaline or chalcedonic silica.... The development of alkalisilica gel in a reactive rock particle can also bring about alteration in the interior pore-structure, so that any inherent tendency to be affected by freezing and thawing will increase." This raises again, but in a somewhat different form, the much-debated problem of alkali-reactive aggregate constituents as contributors to disruption of concrete, for example, the mineral chlorophaeite in some dolerites (Nature, 196, 943; 1962).

Whereas chlorophaeite and certain volcanic rock-types as pebbles have been suspect in causing damage to concrete by virtue of their chemical vulnerability and without the assistance of frost, it is now clear that the incidence of frost may considerably enhance the rate at which disruption of the concrete concerned can happen. Pop-outs produce unsightly 'pock-marks', rather like burst blisters, on concrete surfaces where these physico-chemical mechanisms are at work; they lead to extensive scaling. Four general types are recognized by Mr. Idorn: (a) capillary water in porous pebbles freezing to generate pressure on covering mortar; $(b)$ alkali-aggregate reaction in porous cherts, etc., causing fracturing along a 'reaction rim'; (c) in rocks of very low permeability and negligible capillary water, ice may form on the surface of the pebble, destroying the bond, causing covering mortar or laitance to fall off; $(d)$ growth of microscopic ice lenses in the thin layer of mortar or laitance over the pebble, a variation of type $(c)$.

Pop-outs may not, however, fit all cases of surface deterioration of concreto, especially in circumstances where the potential causes of disintegration and exfoliation of mortar, as outlined above, are not in evidence. Mr. Idorn describes his inspection of a jetty in a Baltic harbour where a thick mass-concrete superstructure has suffered severe deterioration due to exfoliation of the mortar, resulting in pools of water where this disruption has occurred. In this case the aggregates used are said to be of excellent quality, "... strong, impermeable and chemically inert, and ... no reason to question the quality of the cement". The concrete had been exposed to severe frost action involving numerous cycles of freozing and thawing during several winters. Of the type of deterioration, he says: "The aggregate pebbles show no sign of disruption themselves, but severo spalling and exfoliation have taken place on the horizontal faces. . . There are many of the exposed coarser-aggregate pobbles forming pop-outs like the types (c) and (d)..." (above). It is emphasized that there is no sign of chemical roactivity in the aggregates used in this concrete, nor is chemical reaction due to sea-water likoly. the salinity of the Baltic being quite low.

These researches and this particular case of the Baltic jetty are revealing, because they clearly demonstrato the mechanical effects of frost attack on concrete surfaces. whethor accelorated by pop-outs or otherwise. The need for further investigations of similar damage, particularly in other countries where this has occurred, is implicit in this most informative essay. 